\title{
1. Ethics and public policy
}

\section{Jonathan Boston, Andrew Bradstock, and David Eng}

\section{Introduction}

This book is about ethics and public policy. Such a topic immediately raises at least three questions. First, what is ethics? Second, what is public policy? And third, how, and in what ways, are ethics and public policy connected? All three questions have, unsurprisingly, generated large literatures.

Put simply, ethics is about what we ought to do or ought not to do. That is, it is concerned with what is good and bad, right and wrong, just and unjust, or noble and ignoble, and how we can tell the difference. There are many different and often competing ethical frameworks, theories, and principles, and there is certainly no complete agreement about the ethical standards and behaviour that should apply in specific contexts. However, it is generally accepted that the domain of ethics embraces not merely the discrete actions of individuals but also the actions of groups of individuals - whether these groups are small, such as families, or large, such as nations and the international community. Hence, ethical inquiry - or what is often called moral philosophy - is not confined to the private sphere of life; ${ }^{1}$ it is equally relevant to the public realm, including the decisions of those who act on behalf of the public, whether at the national or sub-national level.

Public policy has been defined in many ways, but a relatively uncontroversial approach is to suggest that it is about what governments choose to do and or not to do. ${ }^{2}$ Hence, public policy is concerned primarily with governmental action and inaction. This of course includes both empirical and normative questions. At the empirical level, there are the issues of what governments do in practice and how this varies over time and between jurisdictions. At the normative level, key issues include what governments ought to do and ought not to do, and what principles should guide decision making. From this perspective, then, ethics lies at the heart of public policy and is relevant, as Michael Mintrom argues persuasively in this volume, to all aspects of the policy-making cycle

\footnotetext{
1 Note that there has been much debate about whether a distinction can be made between ethics and morality, as is highlighted by John Uhr's contribution to this volume.

2 For instance, Mark Considine (1994, p. 3) defines a public policy as 'an action which employs government authority to commit resources in support of a preferred value'.
} 
- including the tasks of defining the problem, identifying and assessing the available options, decision making, implementation, evaluation and - where justified - termination.

This of course does not mean that public policy is solely about ethics. Many aspects of policy analysis lack an ethical dimension. For instance, whether a particular country has a policy on nuclear weapons, climate change, refugees, or agricultural subsidies is an empirical matter, for which there is usually a straightforward factual answer. But whether it should have a policy on such matters and, if so, what this policy ought to be, are fundamentally ethical questions. They thus require careful ethical analysis if they are to be answered in a rigorous and justifiable manner.

Just as not all aspects of public policy have an ethical dimension, not all values are ethical values. Mathematical values, for instance, are different in nature and purpose to ethical values. At the same time, we need to be alert: particular statistics or metrics, such as gross domestic product or the consumer price index, often embody or reflect certain ethical assumptions and values, or may be used to justify a certain policy stance, which in turn reflects a particular ethical purpose. Equally, as is widely recognised, the market price of a good or service may not equate to its 'true' worth to society - perhaps because the price fails to take into account the positive and negative externalities associated with the production of the good or service in question. But of course the question of how we should determine the 'true' worth of something raises many profound ethical issues.

This introductory chapter surveys some of the key issues at the interface of ethics and public policy and summarises the main concerns and arguments of the contributors to this volume.

We discuss the relevance of ethics to public policy and explore the various ways in which ethical inquiry is relevant to policy analysis and governmental decision making. We also briefly examine some of the ethical challenges that face public policy practitioners - whether policy analysts, senior advisers, or decision makers - including the problem of conflicting moral imperatives. In so doing, we draw upon and highlight the perspectives of the contributors to Part I of this volume - Tom Campbell, Michael Mintrom, David Bromell, and John Uhr.

We then focus on one of the great moral challenges of the 21 st century, namely how the global community should address the problem of human-induced climate change. The policy issues here are many and varied, and the ethical dilemmas facing humanity are complex and profoundly difficult. For instance, what responsibilities do those living today have to future generations and 
other species? What constitutes a 'dangerous', or alternatively 'safe', amount of climate change? What kind and magnitude of risks are ethically acceptable? How should the burdens of mitigation and adaptation be shared across the international community? And what discount rate should be applied to analyses of the costs and benefits of actions to address climate change? Such questions are discussed by the contributors to Part II of this volume - John Broome; Andy Reisinger and Howard Larsen; Dan Weijers, David Eng, and Ramon Das; and Xavier Márquez.

In the final part of this chapter, we turn to the subject of ethics and the economy. Here, as with climate change, ethics impinges on the nature, regulation, and outcomes of economic activity in multiple ways. What, for instance, is the purpose of economic activity? How does ethical conduct, or the lack thereof, impact on the financial performance of a firm or the economic performance of a nation? For what ends, to what extent, and by what means should we seek to regulate economic activity? To what extent, if at all, has the recent global financial crisis been the product of unethical behaviour, especially by key actors in the financial markets? What policy instruments are available to encourage, or perhaps enforce, particular ethical standards, and what are the costs and benefits of the various regulatory options? Further, it is clear that markets generate unequal outcomes: some people, through their skills, effort, or good fortune, secure substantial wealth; other people, through bad luck, limited capability, or low motivation, remain very poor. But are such unequal outcomes morally acceptable? What are the requirements of distributive justice? And to what extent and by what means should governments redistribute income, whether between people or over the course of a person's lifetime? Further, where the state provides assistance of various kinds to citizens, should such support be conditional or unconditional? Such questions form the heart of the final part of this book and are addressed by Andrew Bradstock, David Rea, Simon Smelt, and Julia Maskivker.

\section{Ethical foundations of public policy}

Let us return, then, to the relationship between ethics and public policy: in what ways is ethics relevant to policy makers and those who advise them? There are at least two issues that are central to policy analysis and that are fundamentally ethical in nature. First, what is policy for? Or, to put it differently, what ends should governments strive to achieve? Second, what are the appropriate means or policy instruments for achieving these ends? Bear in mind that ends and means are closely interrelated: some ends, for instance, are simultaneously the means for achieving other purposes. 
With respect to the purpose of public policy, any answer necessarily entails ethical values. The problem, however, is to determine which particular values should be pursued and what the end should be. On this matter moral and political philosophers have offered many different answers over the centuries. One common approach has been to say that public policy should be directed towards the goal of building the good society, or at least a better one than we currently experience. Others, such as John Rawls (1971), have given pride of place to the quest for justice. Others have argued that the overarching aim should be to realise the common good or the public interest. Still others have invoked theological categories and argued that the role of the state is to uphold the divine will or build the Kingdom of God. And yet others, notably utilitarians such as John Stuart Mill (see Robson 1966), have emphasised the need to maximise utility, happiness, or welfare or achieve the greatest good for the greatest number.

A key issue for many of these approaches is that they beg the question of what is 'good', 'valuable', or 'just'. What, for instance, constitutes a 'good' or 'just' society? What kinds of 'values' - pleasure, happiness, well-being - should be maximised? But setting aside the issue of providing a theory of the good, justice, or value, a related issue is what constitutes a good policy. From the perspective of moral philosophy, there are two broad approaches to answering this question. The first, which is a consequentialist approach, is to assess the goodness or otherwise of a policy solely on the basis of its consequences. But the consequences of a policy are often difficult to discern or may not be fully evident for many years or even decades. Moreover, the consequences may include both positive and negative impacts, and the weighing up of these is often highly controversial. Hence, judging the worth of a policy solely on the basis of its consequences is fraught with problems.

The second approach is to adopt a non-consequentialist or deontological approach, and thus assess a policy not on the basis of its consequences but on whether it is consistent with certain agreed ethical principles. But this raises the issue of what particular principles should count, and, if there are conflicts between the relevant principles, how these should be resolved. Not merely do deontologists favour different ethical principles but they also support different decision-rules for resolving ethical conflicts: some favour giving absolute priority to one particular principle; others favour the use of maximin or maximax rules; ${ }^{3}$ while yet others favour some kind of weighting.

3 Under the maximax approach, the decision rule involves choosing the course of action (or policy option) under which the most fully realised ethical value (across a range of options) is as fully realised as possible. By contrast, under the maximin approach the aim is to choose the course of action (or policy option) where the least fully realised value (across a range of options) is most fully realised. 
Hence, both consequentialist and non-consequentialist approaches encounter problems. How, then, is progress to be made? In the face of ethical doubt and uncertainty, some might argue that the best way forward is for the state to do very little and rely as much as possible on individuals transacting voluntarily through lightly regulated markets. To justify such an approach one or more of the following assumptions might be advanced: that individuals are the source of value (or the sole criterion of value); that all human wants, desires, and preferences are equally meritorious, so have an equal right to be satisfied; and that individuals are the best judges of their own interests. But whether or not such assumptions are justified, the suggestion that by doing very little the state can somehow avoid exercising an ethical judgement concerning what are good or bad policies, or what are good or bad outcomes, is simply flawed. Ethical neutrality by the state is not an option. Choosing to undertake very few tasks involves no less of an ethical judgement than choosing to do a great deal. And both may be wrong.

The only alternative, therefore, is to embrace a particular ethical stance- whether one wants or not. This applies to all levels of government - including national and sub-national government, and to both the political and bureaucratic levels (that is, departments and agencies). A good example of a government department adopting a specific ethical stance is the 'well-being framework' endorsed by the Australian Commonwealth Treasury. To quote Dr Ken Henry, the secretary to the Treasury, in a major speech in late 2009 (pp. 6-7):

Treasury's advice on fiscal policy - as in all other policy areas - is informed by the wellbeing framework that sits at the core of our mission statement. ...

The Treasury's wellbeing framework has five dimensions:

- centrally, the level of freedom and opportunity that people enjoy;

- second, the aggregate level of consumption possibilities;

- third, the distribution of consumption possibilities;

- fourth, the level of risk that people are required to bear; and

- fifth, the level of complexity that people are required to deal with.

Henry goes on to say (p. 7):

Treasury's perspective on freedom and opportunity has been heavily influenced by the work of Amartya Sen on the contribution that 'substantive freedoms' make to development. 
According to Amartya Sen, the true measure of human development is the capabilities that an individual has to choose a life they have reason to value. ... Capabilities allow an individual to fully function in society. They are not income and, while they include basic civil rights and political freedoms, they are not limited to 'rights'.

Later Henry notes (p. 12):

It would be an exceptional case in which a policy intervention would be considered unambiguously positive across all five dimensions. Indeed, the wellbeing framework reflects our conviction that trade-offs matter deeply, emphasising the importance of assessing policy interventions in broad terms.

This is not the proper place to evaluate the Treasury's well-being framework, but several points deserve mention. First, advisory bodies such as treasuries, line departments, and policy taskforces inevitably rely on analytical frameworks in formulating their policy advice to governments. Such frameworks are either explicit and transparent, as in the case of the Australian Commonwealth Treasury, or implicit and opaque. More transparency is arguably better than less. If nothing else, it facilitates easier public scrutiny and more informed democratic debate. Second, analytical frameworks are not ethically neutral. On the contrary, they entail important ethical commitments - that is, commitments about what is valuable and what is not, or what is good and what is bad. The Treasury's framework places a high value on human freedom, opportunities, and capabilities. This represents an ethical choice. Many other choices are possible.

In considering the ethical rationale for any particular policy proposal or objective, it is important to recognise that in many situations it is possible to advance several different justifications. In some cases these may be distinctive and competing, in others overlapping and/or mutually reinforcing. Tom Campbell's contribution to this volume highlights such matters with respect to the challenge of alleviating global poverty. As he observes, it has been common over recent decades for poverty eradication to be justified ethically on the basis of considerations of global justice; indeed, for some, this is the sole justification. But while the pursuit of justice is a critically important ethical imperative, Campbell argues that it is not the only, and perhaps not even the most significant, value of relevance to the issues of global poverty. Instead, he suggests that a more important ethical motivation for reducing poverty is what he calls 'humanity' - that is, the moral duty to alleviate severe suffering for its own stake. In other words, the imperative to relieve hunger and starvation arises out of a basic concern for the well-being of other human beings. This goal of 'humanity', Campbell maintains, is distinct from considerations of justice, and ought to serve as a fundamental ethical driver of public policy. 
Additionally, Campbell advances the proposition that in order to justify and develop a satisfactory policy approach for eradicating global poverty we need to embrace what might be termed 'virtuous prudence' - which he sees as a moral virtue that is distinct from both justice and humanity. Virtuous prudence, in Campbell's view, entails something more than simply enlightened self-interest and includes the notion of mutually beneficial conduct and a concern to provide assistance to the poor and disadvantaged in ways that will minimise dependency and generate increased self-sufficiency. Hence, policy measures to alleviate global poverty need to be designed and implemented with care. While the central goal must be kept sharply in focus, it is also important to recognise that the various policy instruments that are available may have very different implications, including different impacts on the longer-term capabilities and wherewithal of those receiving assistance.

At least two important lessons concerning the relationship between ethics and public policy can be drawn from Campbell's analysis. First, being able to justify policies on multiple ethical grounds has significant potential benefits: not merely does it strengthen the moral case for governmental action and increase the likely level of public support, but it also helps to ensure policies are appropriately crafted to take into account the full range of relevant ethical values. Second, the means and the ends of public policy are closely coupled. They both have ethical dimensions, and these need to be considered simultaneously rather than sequentially.

\section{Ethical policy analysis and advice giving}

For policy makers and their advisers serious ethical reflection on both the purpose of policies and how they should be designed is crucial. But a range of other ethical issues also arise in policy-making contexts. For instance, what norms and values should guide the behaviour of those involved in the policy process? What procedures should be adopted in the event of conflicts of interest? How should the need for secrecy - which is essential for frank and confidential discussions - be balanced against the desirability of openness and public participation? Further, for departmental officials working for a democratically elected government, there are a variety of quite specific ethical issues. For example, to what extent is it legitimate for officials to challenge the priorities and policies of the government? What are the boundaries of free and frank advice or loyal and obedient service? Is it appropriate for officials to advocate for particular social, cultural, economic, or environmental outcomes within the performance of their public duties?

Such issues are explored by two contributors to this volume - Michael Mintrom and David Bromell - both of whom have worked as government officials and 
within an academic context. In his chapter 'Doing ethical policy analysis', Mintrom highlights five ethical principles that should guide policy analysts: integrity, competence, responsibility, respect, and concern. In so doing he emphasises the importance of policy analysts being well connected to the communities that their policies affect and alert to the impacts of their work on the lives of others. Meanwhile, David Bromell proposes a chalcedonian 'distinction without division or separation' between the roles of analysis, advice giving, and advocacy - that is, the interplay between information, interests, and ideology. He identifies principles to guide public servants in maintaining such distinctions and exercising moral judgement within inevitably imperfect democratic processes and institutions, and within a real-world context in which conflicts over facts and values, means and ends, are inescapable. Such an applied ethics requires the active cultivation of what Kenneth Winston (2009) terms 'moral competence in public life'.

The first part of this volume concludes with timely reflections by John Uhr on the limits to ethics in the policy realm. Uhr is not of course suggesting that policy makers should ignore ethical considerations or that we should abandon the task of constructing policies on secure ethical foundations. But he levels three warnings regarding their application. First, he argues that an overemphasis on moral theory runs the risk of dragging the ethics of public policy in the wrong direction towards a world of uncompromising absolutes. The solution is to make a distinction between belief-based morality and practicebased ethics so that we can focus on the practical 'role ethics' of policy makers. Second, central government agencies can promote unrealistic versions of official ethics with a 'one size fits all' approach. The solution, he suggests, is to ensure the 'ethics of office' are appropriately dispersed or context-specific rather than inappropriately uniform or standardised. Third, he cautions policy makers against bypassing the democratic process and using what he calls 'stealth ethics' to guide policy choices. The solution is to put democracy back into ethics by insisting on an ethics of fair procedure as a core foundation of public policy.

\section{Ethics of climate change}

The second part of this volume focuses on the ethics of climate change. As the chapters in this part illustrate, the complex issues related to the problem of climate change and the pressing need to agree on how to avoid its damaging consequences make this problem perhaps the most challenging facing humanity today.

Climate change is both an important ethical issue and a public policy issue. It is an ethical issue simply because it raises the normative question about what 
we should do given that our actions (or our failure to act) have the potential to cause significant harm to ourselves and future generations, as well as other species and the environment. Unlike previous generations, our generation is in the unique position of both knowing the potentially catastrophic consequences of our actions and having the ability to do something about it. If our generation fails to prevent the potentially catastrophic consequences of climate change, this will likely be one of humanity's greatest moral failings.

Climate change is also a critical public policy issue. It is a classic example of a commons dilemma at the global level, a kind of problem where a common property resource or collective good is damaged as a result of individuals in the collective acting in their own self-interest. As such, the problem is one that affects all of us and that all of us can affect. The global scope of the problem means any effective solution can be achieved only through an international agreement that requires individuals and nations to look beyond their immediate self-interest and take into account the interests of others, the broader collective, and future generations. But the causes of this problem go far beyond the actions of particular individuals. They are deeply rooted in institutional practices and structures. The extensive reliance on polluting resources in developed countries goes to the heart of how individuals in these countries live (Jamieson 1992). The fundamental changes that are necessary, therefore, can be achieved only through effective policies and agreements at the national and international levels.

Several factors make the problem of climate change enormously complex from both ethical and public policy perspectives. As already noted, from a purely ethical perspective, climate change raises a wide range of questions. At the most fundamental and theoretical level, there is the question of what is the right or appropriate moral theory to adopt in analysing the problem - a deontological approach that focuses on duties, a consequentialist approach that focuses on consequences, or a virtue theory that focuses on character traits.

The standard approach in environmental economics and public policy has been to use a broadly consequentialist approach, and in particular, a utilitarian cost-benefit analysis, as most prominently illustrated by the review conducted for the British government by Nicholas Stern (2006). The success of this kind of approach, not simply as an economic analysis but one that appropriately reflects ethical values and considerations depends on two broad issues. First, the approach needs to address traditional problems that have been raised for consequentialist/utilitarian approaches, such as whether it is possible to take into account rights, special obligations, and prioritising certain individuals. Second, the approach also requires a plausible theory of value that addresses issues such as (a) how to assess the moral value of current and future people's deaths and our extinction or population collapse and (b) whether the environment has any intrinsic moral value. 
John Broome addresses some of these issues, such as how to assess the moral value of our extinction or population collapse. Although we tend naturally to think that such a consequence is intrinsically bad, Broome argues that preventing a life, or a set of lives, from existing would be bad only if the level of well-being of these potential lives is greater than a neutral level of well-being. Moreover, he argues that even if we assume that future lives have a greater than neutral level of well-being, considerations about our extinction and population collapse can wrongly dominate our analysis of how to respond appropriately to climate change. We can mistakenly think that the most important thing to do is to avoid the unlikely consequence of our extinction or population collapse. Using an expected utility analysis, Broome shows that the small chance of utterly catastrophic climate change (for example, warming of $8^{\circ} \mathrm{C}$ or more) should not dominate our ethical analysis. Instead, we should be equally, if not more, concerned about the harm that moderate to severe climate change will inflict.

Xavier Márquez, in his chapter, explores the merits, tensions, and limitations of using a virtue theory approach in conjunction with the three broad kinds of solutions to collective action problems: technical, external/incentive, and internal/educational (Hardin 1968). In particular, Márquez notes that the research suggests that conditional virtues - virtues that are fragile and sensitive to context - are much more prevalent than robust virtues that are unconditional and less sensitive to context. If Márquez is correct, reliance on a virtue approach and conditional virtues highlights tensions with technical, incentive, and educational-based solutions to commons and collective action problems. For example, technical solutions, such as geoengineering, have the adverse effect of decreasing the inculcation of virtues; individuals have fewer opportunities and less motivation to develop virtuous habits if there is an effective technology for 'solving' the commons problem. And although incentive schemes tend to be more compatible with virtuous behaviour if the appropriate motivations and information are provided, an over-emphasis on external motivating factors can negatively affect the internalisation of virtues.

As a collective action problem, climate change raises ethical challenges that are much broader than simply determining what is ethically right for individuals to do in light of the consequences of their actions, or their duties, or what are virtuous character traits. For instance, it is also morally relevant that some individuals and countries have had a greater role in causing the problem, that some have a greater capability to solve the problem, and that still others are more vulnerable or likely to benefit from any mitigation actions that are taken. In short, one of the fundamental ethical issues raised by climate change is about 
distributive justice or fairness: what is, and how do we determine, the most just or fair way of distributing the responsibilities of dealing with climate change in light of considerations such as those above?

As a problem of distributive justice, climate change is perhaps the most complex ethical problem that humanity has ever faced. In addition to raising theoretical issues about what principles and theories of justice - whether egalitarian, utilitarian, or desert-based - should be used, the problem raises a wide range of ethical considerations given the global and intergenerational dimensions of the problem. How do we account for historical, non-culpable polluting caused by previous generations? Should we prioritise the needs of countries that are worst off and are most vulnerable to the effects of climate change? Do citizens of states have a default entitlement to their current level of well-being? How does a country balance its obligations to its citizens compared with the citizens of other countries? Should future individuals, goods, and services be given the same moral weight as current individuals, goods, and services? As discussed by Andy Reisinger and Howard Larsen, and Dan Weijers, David Eng, and Ramon Das, the success of any of the theoretical approaches to justice depends on whether countries can address these questions, and thus identify the relevant ethical principles (for example, historical and/or culpable responsibility, capability, basic rights and needs, vulnerability, status quo entitlements, equity) and how these should be prioritised.

At the heart of the negotiations on climate change has been the principle of common but differentiated responsibilities and respective capabilities, which has been central to the approach under the United Nations Framework Convention on Climate Change, negotiated in 1992. Although the principle has been almost universally endorsed by the international community, there is no agreement on how it should be interpreted and, in particular, on how the responsibilities should be differentiated. In their chapter, Weijers, Eng, and Das argue for an interpretation of the principle that emphasises basic needs, ability, and culpable responsibility. The two main claims of their view are as follows. First, countries whose citizens do not meet a minimum average level of well-being are licensed to knowingly pollute. Second, all other countries, in proportion to their respective capabilities, bear a three-fold responsibility, namely to account for a) the culpable polluting that they currently cause, b) all non-culpable historical polluting, and c) the permissible polluting caused by the countries whose citizens do not meet a minimum average level of well-being.

For public policy makers, many of the significant challenges are not simply theoretical or ethical. Any real solution to the problem of climate change, in addition to being just, needs to be effective, practical, and politically achievable. For example, the problem of justifying why we should prioritise climate change over other pressing aims, such as the recent global financial crisis, presents 
a significant political challenge for public policy makers and officials. Large parts of the population continue to raise the issue of empirical uncertainty, so continue to be sceptical about the science of climate change and whether we can be certain about its causes and effects. Although these doubts are not surprising - especially given the impact that policies such as emissions trading schemes and emissions taxes are likely to have on large parts of the population they are irrational. On any reasonable cost-benefit analysis of the problem, the magnitude of the harmful consequences of climate change and the risks of the impacts far outweigh any concerns about empirical uncertainty.

The far more daunting challenge facing public policy makers arises from the interdisciplinary nature of the problem. Beyond the purely ethical complexities described earlier, any effective solution obviously needs to rely on a scientific analysis to identify the causes and effects of climate change as well as effective strategies for mitigation and adaptation. At the same time, public policy makers need an economic analysis of the costs and benefits of potential strategies and policies. The issues that arise from analysing the problem from each of these perspectives are, of course, enormously complex.

The interdisciplinary nature of the problem of climate change does not arise merely from the fact it requires analyses from many different perspectives scientific, economic, ethical, and political. As Reisinger and Larsen discuss, many of the key concepts at the heart of the debate on climate change are inherently interdisciplinary. 'Key vulnerabilities', 'dangerous climate change', and 'acceptable risks', for example, can be defined only on the basis of both scientific and ethical analyses. Likewise, determining the appropriate discount rate - a key concept in any cost-benefit analysis that reflects the value of goods and service in the future compared with today - can be informed only by both economic and ethical analyses. Of course, drawing on different disciplinary perspectives is not without its challenges, but, as highlighted in this volume, it can enrich our understanding and deepen our appreciation of the complexity and gravity of the issues at stake. Arguably, the problem of climate change illustrates this better than any other contemporary ethical or policy dilemma.

\section{Perspectives on ethics and the economy}

The final part of this book looks at issues related to 'economics', in particular the relationship between ethical behaviour and the functioning of markets, the question of how far markets should be regulated, the moral dilemma of 'freeloading' in systems that allocate welfare benefits unconditionally, and the challenges posed by rising economic inequality. Forming a backdrop to this section is the global financial crisis that first shook the world in 2008, and 
three of the chapters engage directly with that crisis. Many commentators viewed this crisis as a consequence of highly unethical behaviour on the part of people in the financial and banking industry, prompting calls for a radical re-examination of the way markets operate and a fresh look at issues such as accountability, regulation, and control. These calls directly and indirectly inform the contributions to this part.

It is tempting to conclude that the global economic downturn offered a stark illustration of what can happen when ethics gets uncoupled from economics, when markets are allowed to operate in a totally 'unfettered' way. In the ever more brutal 'dog eat $\operatorname{dog}^{\prime}$ world of contemporary capitalism what matters most is securing global brand recognition, improving shareholder returns, and discovering ever more imaginative ways of 'making money from money'. The voices seeking to highlight the human consequences of economic activity, or calling for moral restraint in the interests of 'the common good', seem like ever fainter cries in a more and more inhospitable wilderness. Yet it was not ever thus, for as R. H. Tawney reminded his readers nearly a hundred years ago, the gradual separation of ethics from economics was really only set in train with the development of capitalism. Until then, Tawney noted, economic thought had been understood as part of a hierarchy of values embracing all human interests and activities (cited in Gorringe 1994, pp. 31-2). Now we could say that the situation is reversed to the extent that, for many economists and politicians, the global economy is the system within which everything else is subsumed. As such, the global economy is able, as Jonathon Porritt writes, to 'define its own operational boundaries' (Porritt 2007, p. 56), to effectively close down space for ethical questions rooted in a discourse situated outside those boundaries. As Washington-based commentator Jim Wallis has argued, we have now succeeded in substituting 'market value' for 'moral values', with the market replacing "much of the moral space of society, even questioning the value of having "moral space" where the market does not reach' (Wallis 2010, p. 28).

When a former UK prime minister, Gordon Brown, suggested that the unsupervised globalisation of our financial markets did not only cross national boundaries [but] moral boundaries too' (Brown and Rudd 2009), he reflected the view of many influential figures in politics, the academy, the media, and the church that 'the market' and 'ethics' needed to become reacquainted. Calls for greater regulation of markets, for measures to ensure more responsible lending, for action to restrain what was seen as the 'greed' of banks and finance houses, were voiced in parliaments, in pulpits, in news-rooms, and on the streets. Developments such as the introduction of a currency transaction levy in the United Kingdom, essentially a tax on the banking sector to raise new money for international development, suggest these calls have not entirely fallen on deaf 
ears. Yet as the contributors to this volume argue, the issues behind the global crisis were multifaceted and diverse, and the ethical questions they raised complex and involved.

Simon Smelt considers the oft-recited claim that the root of the crisis lay in the 'greed' of people operating in the market, as if this were somehow a new phenomenon (as in Alan Greenspan's assertion in 2008 that people 'got greedy' (cited in Goodman 2008)). Greed, Smelt notes, is hardly new, and in fact we have developed over the years a better idea of how to harness it: legislation has been in place for years to curb excessive pay and benefits for bankers, for example. We just did not ensure it was enforced. The question of governance and regulation in the banking sector is also more complex than sometimes imagined, Smelt argues, since it was the better governed and regulated banks that got themselves into the most trouble, not those we might see as 'laggard'. The technology was there but, again, it failed when needed. Indeed, Smelt notes, after considering a range of factors in the crisis, the root of the crisis lay not in any lack of regulation or risk analysis in the financial sector but in the practice of ethical policy and governance through established principles of dayto-day fairness applied so as to build and earn trust'. The 'moral dimension' underlying the economic crisis, in other words, stemmed from a weakness in the commutative justice that underpins the marketplace. This was not a crisis brought about by a shortage of 'trust' - another myth Smelt seeks to challenge - but by trust in modern sophisticated risk analysis and regulatory techniques being misplaced.

David Rea offers a different but complementary take on the question of how ethical behaviour can be understood within an economic context, arguing that a direct relationship exists between such behaviour and economic efficiency. Starting, as Smelt did, with the global financial crisis and the debate around its origins and causes, Rea argues that the crisis provides us with a compelling example of how poor ethical standards within business can result in adverse economic consequences. For Rea, ethical behaviour in the context of economic activity involves individuals balancing their personal self-interests and the interests of others - forgoing, perhaps, a course of action that would benefit them in favour of one that benefits others - and he argues that, while selfish behaviour can lead to markets functioning badly or failing altogether, ethical behaviour can be seen to increase their efficiency. Taking as a case study the practice of contracting, Rea shows how, for example, the construction of safeguards against the risk of opportunism on the part of the other party can be costly, and how the costs involved not infrequently mean that parts of the process, or indeed of the contract itself, are left incomplete. Thus, the extent to which individuals act selfishly is material to the overall cost of contracting, and where ethical behaviour is more prevalent, the process is both cheaper and more 
efficient. Rea adduces evidence to show that countries where ethical behaviour is more widespread tend to be richer than those with lower measured ethics. He argues that New Zealand, despite already having a relatively high ranking on the 'index of ethical behaviour', might be able to reach the income levels of Australia if it had a level of ethical behaviour akin to that of Switzerland.

Given the focus of his chapter, Rea notes, but chooses not to develop, the argument that ethical behaviour in an economic context might lead to a 'fairer' distribution of resources. Smelt, too, touches on the issue of 'distributive justice', although he suggests the pursuit of such a goal through the market can be shown to weaken its 'workings', even that attempts to pursue it may have exacerbated the global crisis. In his chapter, Andrew Bradstock does indeed see tackling economic inequality as an ethical imperative, and argues that both on theological and sociological grounds the case can be made for governments to pursue policies aimed, not just at reducing poverty, but at narrowing the gap between 'rich' and 'poor'. Bradstock's case rests on two lines of reasoning. First, the Judaeo-Christian principle that all people are created with equal value places a responsibility on communities to ensure that none of their members is unable to meet their basic needs. Second, current research in the area of public health demonstrates that one of the key factors behind dysfunctional societies is their level of economic inequality. Just as the biblical narratives suggest that measures to prevent economic inequality becoming entrenched will enhance the health and well-being of a community and its individual members, contemporary research indicates that even small reductions in inequality can result, not just in fewer poor people, but in safer, more trusting, and more cohesive societies to the benefit of all their members. Therefore, countries with relatively high levels of inequality, such as New Zealand, Australia, and the United Kingdom, could usefully consider measures aimed at reducing inequality, and while these will inevitably involve a degree of central coordination, they do not imply a return to the 'big state'. Indeed, Bradstock argues, a wide variety of mechanisms might be adopted to narrow inequality, and only an approach that moves beyond old ideological divisions would be likely to succeed.

One area that Bradstock suggests will need to be addressed if inequality is to be tackled effectively is the provision of social assistance (or social welfare). Julia Maskivker examines this subject in detail in her chapter, focusing on the debate over whether the provision of 'unconditional' welfare is compatible with well-accepted principles of justice. Is it fair, for instance, for people to enjoy the benefits of the system without contributing to it? And is it reasonable for hardworking taxpayers to fund the benefits of those who opt not to work when in practice they could? Maskivker notes the force of this 'free-rider' argument against unconditional welfare benefits, and highlights the fact that defenders of unconditionality have yet to come up with a satisfactory rebuttal. 
The strongest counter-argument thus far is that the option to exit cooperation is not unjust because it is equally available to everybody. But Maskivker criticises this contention on the grounds that assessing the 'justness' of a given situation cannot be undertaken simply by evoking 'a distributive criterion as the primordial index of fairness'. Free-riding, in other words, could be said to be by nature unjust, regardless of how many people are in a position to take advantage of it.

Taking up the challenge to find a better refutation, and drawing on the work of John Rawls (1972) and H. L. A. Hart (1955), Maskivker develops her own response to the 'free-rider' objection to unconditional welfare benefits. Her argument, in short, is that freedom from cooperation in the generation of social benefits is justified on the basis of injustice in the design of the cooperative scheme and the non-voluntary nature of that scheme.

Like Bradstock, Maskivker also places a high priority on the fulfilment of 'basic human needs', and one conclusion to draw from this section is that the ultimate ethical criterion for measuring economic arrangements must be the extent to which they enhance and promote the good life for all. This brings us back to Campbell's assertion at the beginning of this book, and which runs like a leitmotif throughout each of its parts, that a primary ethical driver of public policy must be a basic concern for the well-being of others.

\section{References}

Brown, G., and K. Rudd. 2009. 'Speech and Q\&A at St Paul's Cathedral.' London, 31 March. http://webarchive.nationalarchives.gov.uk/+/number 10. gov.uk/news/speeches-and-transcripts/2009/03/pms-speech-at-st-paulscathedral-18858.

Considine, M. 1994. Public Policy: A critical approach. South Melbourne: Macmillan.

Goodman, P. 2008. 'Taking hard new look at a Greenspan legacy.' New York Times, 8 October. www.nytimes.com/2008/10/09/business/economy/09greenspan. html.

Gorringe, T. J. 1994. Capital and the Kingdom: Theological ethics and economic order. Maryknoll, NY: Orbis.

Hardin, G. 1968. 'The tragedy of the commons.' Science 162(3859): 1243-8.

Hart, H. L. A. 1955. 'Are there any natural rights?' Philosophical Review 64(2): $175-91$. 
Henry, K. 2009. 'Fiscal policy: More than just a national budget.' Address to the 2009 Whitlam Institute Symposium, 30 November. www.treasury.gov. $\mathrm{au} /$ documents/1678/HTML/docshell.asp?URL=Whitlam_Institute_Speech. htm.

Jamieson, D. 1992. 'Ethics, public policy, and global warming.' Science Technology and Human Values 17(2): 139-53.

Porritt, J. 2007. Capitalism as if the World Matters. London: Earthscan.

Rawls, J. 1972. A Theory of Justice. London: Oxford University Press.

Robson, J (ed.). 1966. John Stuart Mill: A selection of his works. New York: Odyssey Press.

Sen, A. 2009. The Idea of Justice. London: Allen Lane.

Stern, N. 2006. The Economics of Climate Change: The Stern Review. Cambridge, UK: Cambridge University Press.

Wallis, J. 2010. Rediscovering Values: On Wall Street, Main Street, and Your Street. New York: Howard Books.

Winston, K. 2009. Moral Competence in Public Life. Occasional paper 4. Melbourne: Australia and New Zealand School of Government and State Services Authority. www.ssa.vic.gov.au/CA2571410025903D/WebObj/ OccPaper_04_Winston/\$File/OccPaper_04_Winston.pdf. 